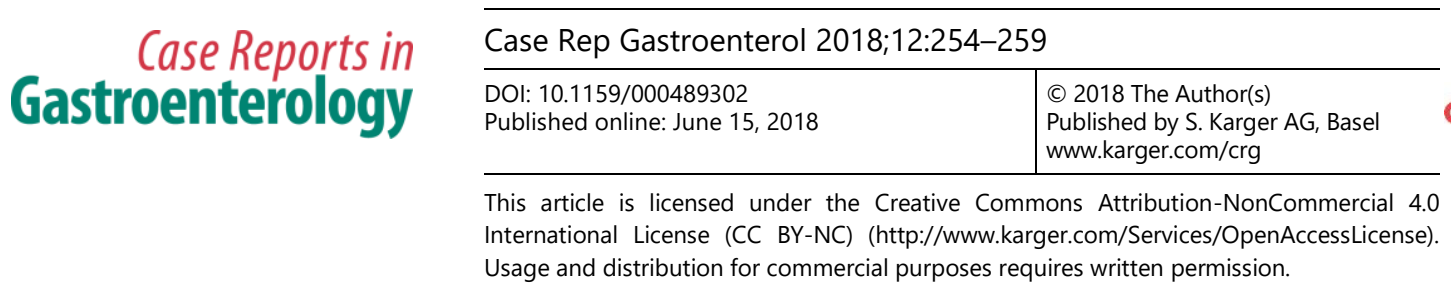

\title{
Phlegmonous Proctitis: A Rare Entity of the Presentation of Proctitis
}

\author{
Apichat Kaewdech Pimsiri Sripongpun \\ Division of Gastroenterology and Hepatology, Department of Internal Medicine, Faculty \\ of Medicine, Prince of Songkla University, Hat Yai, Thailand
}

\section{Keywords}

Phlegmonous proctitis $\cdot$ Rectum $\cdot$ Rectosigmoid colon $\cdot$ Colonoscopy $\cdot$ Biopsy

\begin{abstract}
Phlegmonous proctitis is a rare condition; it was first described in 1940. We report the case of an elderly woman who presented with acute severe lower abdominal pain, tenesmus, and fever. A computed tomography of the whole abdomen revealed a long segment of circumferential wall thickening of the rectum and rectosigmoid colon. Colonoscopy was done subsequently and showed marked edematous and erythematous rectal mucosa. When rectal tissue biopsy was performed, a large amount of pus came out at the biopsy site, which led to the diagnosis of phlegmonous proctitis.

(C) 2018 The Author(s)

Published by S. Karger AG, Basel
\end{abstract}

\section{Introduction}

Phlegmonous proctitis is an uncommon condition; it was first described in 1940 by Yaker [1], and there was no other case report since then. The first case was a woman who had postpartum rectal pain. The author hypothesized that the cause of phlegmonous proctitis might be the chemical irritation following paraldehyde and soap enema [1]. This is the second case report of phlegmonous proctitis. There is little knowledge about this condition. Like in phlegmonous gastritis, which is a suppurative bacterial infection of the gastric wall, the clinical course is rapidly worsening and results in a high mortality [2]. 


\section{Case Reports in Gastroenterology}

Case Rep Gastroenterol 2018;12:254-259

DOI: $10.1159 / 000489302$

c 2018 The Author(s). Published by S. Karger AG, Basel www.karger.com/crg

Kaewdech and Sripongpun: Phlegmonous Proctitis: A Rare Entity of the Presentation of Proctitis

\section{Case Presentation}

A 68-year-old Thai woman with type 2 diabetes had Child-Turcotte-Pugh B cirrhosis suspected to be due to nonalcoholic steatohepatitis and adjustment disorder. Her current medications were omeprazole $20 \mathrm{mg} /$ day, aspirin $81 \mathrm{mg}$ once daily, multivitamin twice daily, lactulose p.r.n., and glicazide $30 \mathrm{mg}$ once daily. She presented with severe lower abdominal pain for $12 \mathrm{~h}$. Two days prior to admission, she had lower abdominal pain with cramping and tenesmus. She tried to defecate several times, but no fecal material came out. She also had agitation and fever with chills, but no other organ-specific symptom was observed. Her daughter then brought her to the emergency department. On physical examination, her body temperature was $38.4^{\circ} \mathrm{C}$, pulse rate was 84 beats per minute, blood pressure was $140 / 60 \mathrm{~mm} \mathrm{Hg}$, and respiratory rate was 24 breaths per minute. Abdominal examination revealed marked abdominal distension, low midline surgical scar, normal bowel sound, and moderate tenderness with voluntary guarding at the lower abdomen, especially at the left lower quadrant; liver and spleen were not palpable. Mucous bloody stool was obtained from digital rectal examination. The laboratory test revealed hematocrit $27.3 \%$, white blood cell count $13.2 \times 10^{9} / \mathrm{L}$, PMN $92 \%$, band $5 \%$, and platelet count $58 \times 10^{9} / \mathrm{L}$, as well as stable hematocrit and platelet count compared to the previous follow-up visit. The electrolytes showed wide anion metabolic acidosis and hyperlactatemia level of $7 \mathrm{mmol} / \mathrm{L}$. Hemoculture was taken but showed no growth of bacteria. Stool exam showed numerous white blood cells without trophozoite of Entamoeba histolytica on iodine stain as well as negative rectal culture for bacteria. She underwent computed tomography of the whole abdomen which showed a long segment of circumferential wall thickening, about $0.9-2.0 \mathrm{~cm}$ in thickness, involving the rectum, surrounded by moderate fat reticulation (Fig. 1). Ceftriaxone and metronidazole were given intravenously. Colonoscopy was subsequently performed 2 days later since there was no significant improvement of her clinical condition. The colonoscopic findings were severe edematous, erythematous mucosa with multiple small ulcers and exudation at the top of the rectum; the rest of the colon, including the terminal ileum, were normal (Fig. 2). A biopsy was taken at the rectum, and there was a large amount of pus discharge from the biopsy site. A rectal tissue culture was obtained and revealed Escherichia coli and Klebsiella pneumoniae ESBL strain organisms.

The histopathology of the biopsy specimens was consistent with debris and ulcer with crypt abscess at the rectum (Fig. 3). Hence, phlegmonous proctitis was diagnosed from a combination of her imaging and colonoscopic findings and the histopathological report. After drainage of pus discharge by biopsy of the rectal mucosa, accompanied by continued ceftriaxone and metronidazole treatment, her clinical condition gradually improved, the fever was gone, and there was no more abdominal pain; normal bowel movement then followed. The follow-up computed tomography of the abdomen 3 weeks after treatment showed marked improvement of circumferential wall thickening at the rectum (Fig. 4).

\section{Discussion}

Phlegmonous proctitis is a rare entity that was mentioned for the first time in 1940 by Yaker [1]. We carried out a bibliographic search using the PubMed database with the keyword "phlegmonous proctitis." There was no other case report since then; we here describe the second case of phlegmonous proctitis.

The first case report by Yaker [1] described a woman who presented with postpartum rectal pain and purulent feces after using paraldehyde and soap enema in labor pain and after 
postpartum. He followed up the patient and found a rectal stricture after that. The hypothesis was that the cause of phlegmonous proctitis might be the chemical irritation and injury of the rectal mucosa. Our case is totally different from the first case in terms of underlying clinical conditions, and no previous history of rectal enema was present in our case. Nonetheless, the pain in the rectum and lower abdomen were similar.

"Phlegmonous" is a term that means mass-like forming of the gastrointestinal tract that is caused by suppurative bacterial infection. Among various sites of the gastrointestinal tract, the term "phlegmonous gastritis," the suppurative infection of the gastric wall [3], is the most well-known and widely described. The presentation of phlegmonous gastritis is nonspecific; typical clinical manifestations are epigastric pain, vomiting, and fever [3, 4]. The diagnosis was difficult in the early phase according to nonspecific manifestations. Risk factors include postprocedures (such as esophagoduodenoscopy with biopsy, endoscopic submucosal resection), alcohol consumption, immunosuppression, chronic gastritis, drugs, and mucosal injury [2, 5]. However, the risk factors of phlegmonous proctitis are unclear. In the first case, chemical irritation from rectal enema was presumably the cause of this condition, but in our case, there was no such history of enema. We hypothesize that our patient's medical history of diabetes and cirrhosis may have led to an immunocompromised status and might have been a risk factor for developing phlegmonous proctitis.

The diagnosis of phlegmonous proctitis was made with comprehensive modalities, including computed tomography of the abdomen, colonoscopy, and histopathological study. There are no data regarding the common microbiology of this condition. In phlegmonous gastritis, the common pathogens found were Streptococcus spp. (57\%) and Enterococcus (10\%) [2]. In our case, tissue cultures were positive for Escherichia coli and Klebsiella pneumoniae ESBL strain; nevertheless, these organisms could not be the only colonization since the patient had a good response to ceftriaxone and metronidazole, to which these organisms are not sensitive. The follow-up computed tomography of the abdomen 3 weeks after treatment showed marked improvement of phlegmonous proctitis. The causative organisms may be gram-negative bacteria and anaerobes.

\section{Statement of Ethics}

Informed consent was obtained for this case report.

\section{Disclosure Statement}

The authors have no conflicts of interest to disclose.

\section{Funding Sources}

There are no funding sources to report.

\section{Author Contributions}

Both authors participated in writing the manuscript. A. Kaewdech is the article guarantor. 


\section{Gastroenterology}

\begin{tabular}{l|l}
\hline DOI: 10.1159/000489302 & (c) 2018 The Author(s). Published by S. Karger AG, Basel \\
\hline
\end{tabular} www.karger.com/crg

Kaewdech and Sripongpun: Phlegmonous Proctitis: A Rare Entity of the Presentation of Proctitis

\section{References}

1 Yaker DN. Phlegmonous proctitis. Am J Surg. 1940 Aug;49(2):393-5.

2 Rada-Palomino A, Muñoz-Duyos A, Pérez-Romero N, Vargas-Pierola H, Puértolas-Rico N, Ruiz-Campos L et al. Phlegmonous gastritis: a rare entity as a differential diagnostic of an acute abdomen. Description of a case and a bibliographic review. Rev Esp Enferm Dig. 2014 Jun;106(6):418-24.

3 Schultz MJ, van der Hulst RW, Tytgat GN. Acute phlegmonous gastritis. Gastrointest Endosc. 1996 Jul;44(1):80-3.

4 Lawrence JS. Phlegmonous Gastritis. Boston Med Surg J. 1926;195(17):800-3.

5 Kato K, Tominaga K, Sugimori S, Nagami Y, Kamata N, Yamagami H et al. Successful Treatment of Early-Diagnosed Primary Phlegmonous Gastritis. Intern Med. 2015;54(22):2863-6.
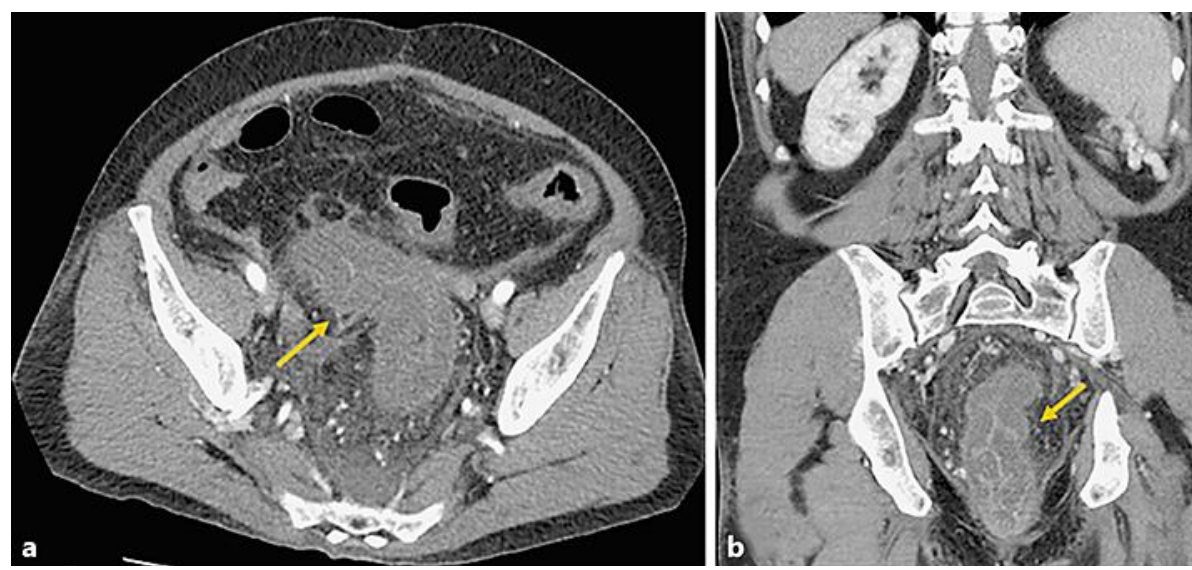

Fig. 1. Computed tomography of the abdomen, axial view (a) and coronal view (b), showing circumferential wall thickening at the rectum. 


\section{Case Reports in Gastroenterology}
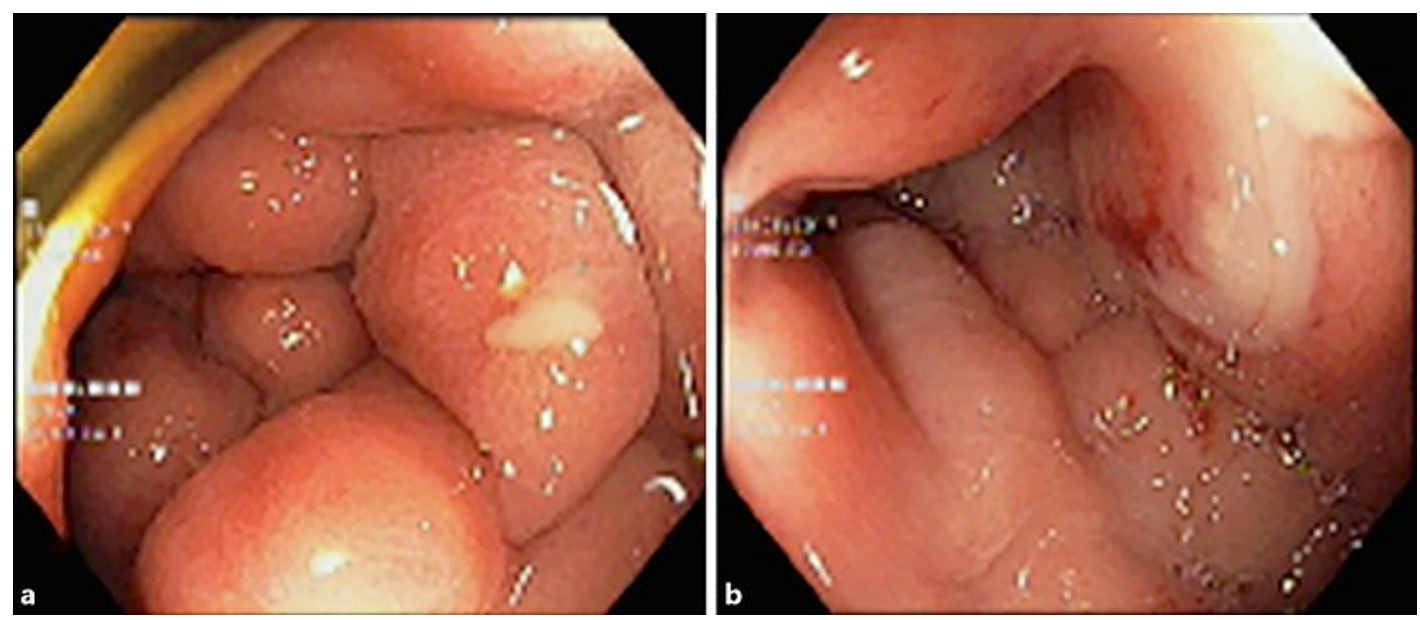

Fig. 2. a Colonoscopy showing severe edematous, erythematous mucosa with multiple ulcers and exudate at the rectum. b Pus discharge at the biopsy site.

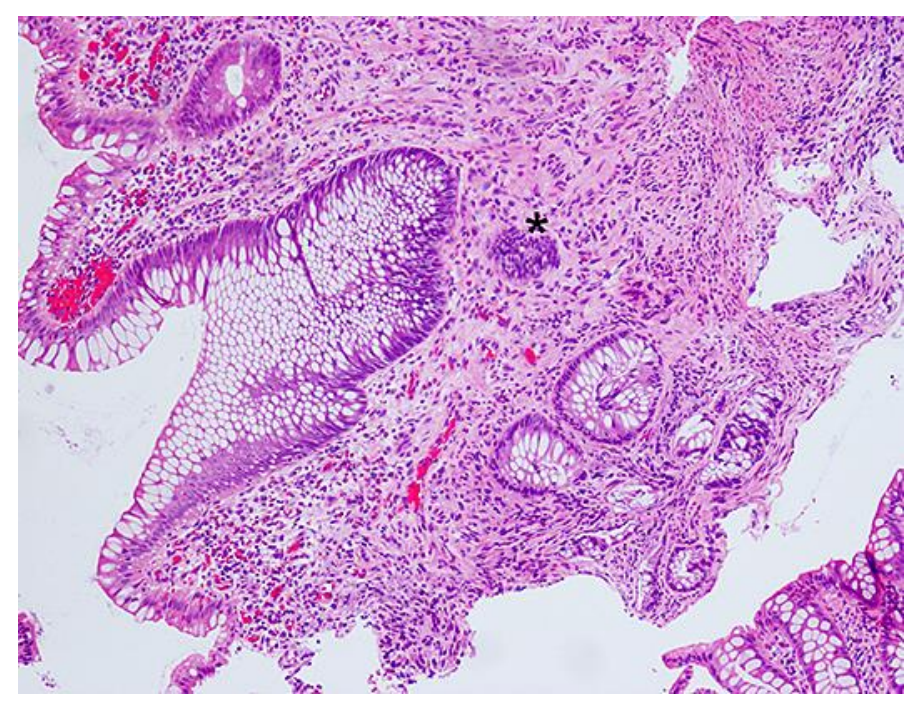

Fig. 3. HE stain showing acute inflammation of mucosa and neutrophilic abscess in submucosa of the rec$\operatorname{tum}(\times 100)$. 

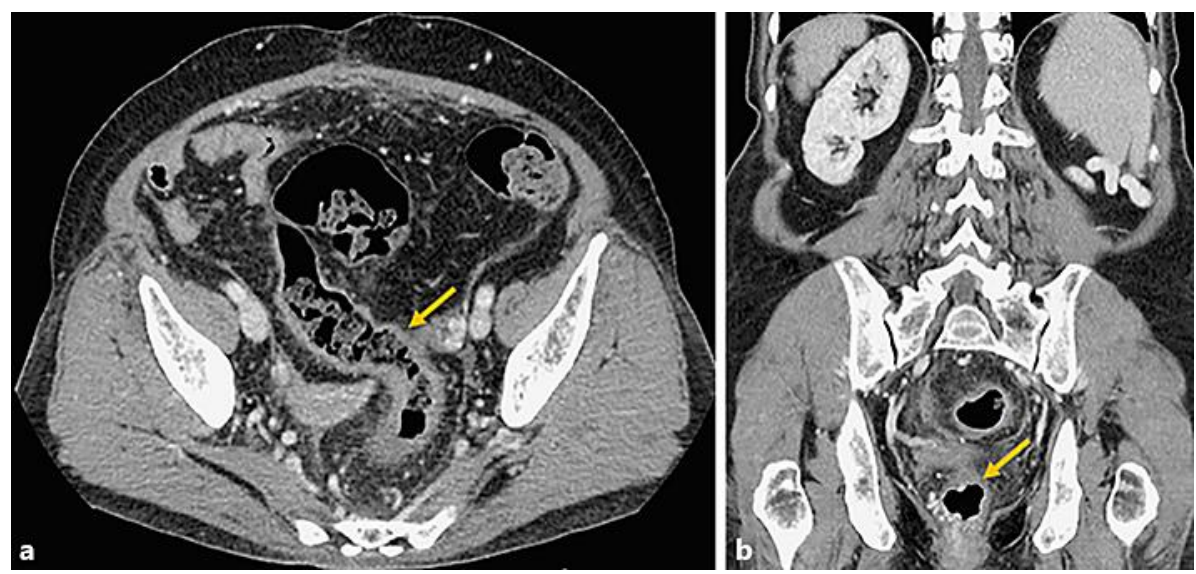

Fig. 4. Computed tomography of the abdomen, axial view (a) and coronal view (b), after 3 weeks of antibiotics treatment showing marked improvement of phlegmonous proctitis. 